\title{
REINFUSION OF MEDIASTINAL BLOOD AFTER HEART SURGERY
}

Jocelyne Martin, MD

Danielle Robitaille, $\mathrm{MD}^{\mathrm{c}}$

Louis P. Perrault, MD, $\mathrm{PhD}^{\mathrm{a}}$

Michel Pellerin, $\mathrm{MD}^{\mathrm{a}}$

Pierre Pagé, MD

Norman Searle, $\mathrm{MD}^{\mathrm{b}}$

Raymond Cartier, MD

Yves Hébert, $\mathrm{MD}^{\mathrm{a}}$

L.Conrad Pelletier, MD

Howard T. Thaler, $\mathrm{PhD}^{\mathrm{d}}$

Michel Carrier, MD ${ }^{\mathrm{a}}$
Background: Several authors studying autotransfusion of shed mediastinal blood in patients undergoing heart operations have published conflicting results regarding reduction of the need for homologous blood transfusion. The effect on coagulation parameters is also unclear.

Methods: In a prospective randomized study, 198 patients who underwent coronary artery bypass grafting or a valvular operation were divided into 2 groups: a group with autotransfusion of shed mediastinal blood after an operation and a control group. Continuous reinfusion of mediastinal blood was done until no drainage was present or for a period of 12 hours after the operation. The amount of blood lost and autotransfused, the number of homologous blood products transfused, and the coagulation parameters were monitored.

Results: The number of patients requiring homologous blood transfusion was significantly different between the 2 groups (54/98 [55\%] in autotransfused patients vs $73 / 100[73 \%]$ in the control group, $P=.01)$. The number of reexplorations for excessive bleeding was similar in the 2 groups (7/98 [7.1\%] vs $8 / 100[8 \%]$ ), but the amount of blood collected postoperatively was higher in the autotransfused patients compared with control patients $(1200 \pm 201$ $\mathrm{mL}$ vs $758 \pm 152 \mathrm{~mL}, P=.0007)$. Coagulation parameters analyzed and complication rates were similar in the 2 groups after the operations.

Conclusion: Autotransfusion of shed mediastinal blood reduces the need for homologous blood transfusion in patients undergoing various cardiac operations. The cause of increased shed blood in patients undergoing autotransfusion remains unclear. (J Thorac Cardiovasc Surg 2000;120:499-504)
$\mathrm{R}$ einfusion of blood collected from the mediastinum of patients after cardiac operations was first reported by Schaff and colleagues ${ }^{1}$ in 1978 . Since then, many studies have suggested that reinfusion may help decrease the number of homologous transfusions needed in the postoperative period. ${ }^{2-5}$ On the other hand, conflicting results have also been published, and identification of subgroups of patients who might especially

From the Departments of Surgery ${ }^{\mathrm{a}}$ and Anesthesia ${ }^{\mathrm{b}}$ and the Laboratory of Hematology, ${ }^{\mathrm{c}}$ Montreal Heart Institute and University of Montreal, Montreal, Quebec, Canada; and Biostatistics Consulting Service, ${ }^{\mathrm{d}}$ Memorial Sloan-Kettering Cancer Center, New York, NY.

Received for publication Feb 11, 2000; revisions requested March 27, 2000; revisions received April 20, 2000; accepted for publication May 17, 2000.

Address for reprints: Michel Carrier, MD, Department of Surgery, Montreal Heart Institute, 500 Belanger St E, Montreal, QC H1T 1C8, Canada (E-mail: carrier@icm.umontreal.ca).

Copyright (C) 2000 by The American Association for Thoracic Surgery

0022-5223/2000 \$12.00+ $0 \quad \mathbf{1 2 / 1 / 1 0 8 6 9 1}$

doi: $10.1067 / \mathrm{mtc} .2000 .108691$ benefit from reinfusion has been difficult. ${ }^{6-9}$ Some authors have questioned the safety of mediastinal blood reinfusion regarding a possible association with coagulopathy, ${ }^{10}$ but this technique has been clinically proven safe, although not necessarily useful. ${ }^{11-13}$

Recently, de Varennes and associates ${ }^{3}$ reported their experience with reinfusion of mediastinal shed blood after first-time isolated coronary artery bypass operations in 337 patients. They showed a significant decrease in total exposure to homologous transfusions: $48 \%$ of patients in the autotransfusion group received homologous transfusions compared with $82 \%$ in the control group. Because this study compared 2 nonrandomized groups of patients (a historical control study), the methodologic design can be criticized.

Still debated, the role of autotransfusion of mediastinal shed blood remains of concern because approximately $60 \%$ of patients undergoing heart operations in our institution receive homologous blood transfusions in the postoperative period. In addition to the infectious and immune reaction risks associated with blood transfusions, the newly introduced modality of distribution 
Table I. Characteristics of the 2 patient groups

\begin{tabular}{lccc}
\hline \multicolumn{1}{c}{ Characteristics } & Reinfusion group & Control group & P value \\
\hline No. of patients & 98 & 100 & .009 \\
Age $(\mathrm{y})$ & $62 \pm 2$ & $66 \pm 2$ & .3 \\
Sex $(\mathrm{M} / \mathrm{F})$ & $75 / 23$ & $70 / 30$ & .008 \\
Weight $(\mathrm{kg})$ & $79 \pm 3$ & $73 \pm 3$ & .006 \\
Body surface area & $1.87 \pm 0.04$ & $1.79 \pm 0.04$ & .002 \\
Hemoglobin $(\mathrm{g} / \mathrm{L})$ & $121 \pm 3$ & $114 \pm 3$ & .0007 \\
Red cell mass ${ }^{*}\left(\mathrm{~g} \cdot \mathrm{L}^{-1} \cdot \mathrm{m}^{-2}\right)$ & $227 \pm 8$ & $206 \pm 9$ & .8 \\
Platelets $\left(\times 10^{9} / \mathrm{L}\right)$ & $169 \pm 9$ & $170 \pm 10$ & .5 \\
Preoperative aspirin (within 7 days) & $12 \%$ & $16 \%$ & .7 \\
Preoperative intravenous heparin & $36 \%$ & $33 \%$ & \\
\hline
\end{tabular}

${ }^{*}$ Red cell mass $=$ Body surface area $\times$ Hemoglobin.

Table II. Type of surgical procedures

\begin{tabular}{lccc}
\hline \multicolumn{1}{c}{ Procedures } & $\begin{array}{c}\text { Reinfusion } \\
\text { group } \\
(n=98)\end{array}$ & $\begin{array}{c}\text { Control } \\
\text { group } \\
(n=100)\end{array}$ & P value $^{*}$ \\
\hline CABG only (\%) & $74(76)$ & $76(76)$ & 1 \\
Valve only (\%) & $14(14)$ & $18(18)$ & .6 \\
CABG and valve (\%) & $10(10)$ & $6(6)$ & .3 \\
Redo (\%) & $6(6)$ & $9(9)$ & .6 \\
\hline
\end{tabular}

of blood products in the Canadian health system will engender extra costs to hospitals having a high consumption of these products. Hence any strategy designed to decrease the number of homologous transfusions is of great interest.

We therefore undertook a prospective randomized clinical trial to compare the current approach of mediastinal drainage without reinfusion to a system specifically designed for reinfusion. The primary aim of our study was to determine the effect of reinfusion on the percentage of patients requiring any type of homologous blood product transfusions and on the number of blood product units transfused per patient after a heart operation. Secondarily, we wanted to measure the effects of reinfusion on blood levels of hemoglobin, platelets, and coagulation parameters. Finally, we looked to define which category of patients would most benefit from reinfusion of mediastinal shed blood after cardiac operations.

\section{Methods}

Study population. From September 1998 to January 1999, patients admitted to our institution for coronary artery bypass grafting operations, valvular replacement, or both procedures under cardiopulmonary bypass (CPB) were offered the option to participate in the study. Written informed consent was obtained from all recruited patients after explanation of the potential risks and benefits of the study approaches. Patients with a prior history of cardiac intervention were also eligible. Exclusion criteria consisted of preoperative known coagulopathy or patients unable to give an informed consent.

Technical procedure. In the control group, postoperative mediastinal drainage was achieved by the currently used system that consists of $24 \mathrm{~F}$ double-lumen soft sump drains under high-pressure wall suction, from which collected blood is discarded. In the treatment group, mediastinal drainage was achieved with a commercially available autotransfusion system (Atrium Medical Corporation, Hudson, NH). This reinfusion system consists of $28 \mathrm{~F}$ thoracic tubes connected to a 3-chamber system: a collection chamber, an underwater seal chamber, and a $20-\mathrm{cm}_{2} \mathrm{O}$ suction control chamber. The $500-\mathrm{mL}$ capacity sterile collection chamber contains $20 \mathrm{~mL}$ of adenine-supplemented citrate dextrose. All collected blood is filtered through an $80-\mu \mathrm{m}$ filter and autotransfused to the patient hourly until no drainage was present or for a maximum of 12 hours. The reinfusion was started 1 hour after the arrival of the patient in the intensive care unit.

Operative procedure. Perioperative management was standard. During the operation, heparin was administered as a $3-\mathrm{mg} / \mathrm{kg}$ bolus with possible additional doses to maintain the activated clotting time above 400 seconds throughout the $\mathrm{CPB}$ time. Anticoagulation was reversed with a $3-\mathrm{mg} / \mathrm{kg}$ dose of protamine sulfate. The use of an antifibrinolytic agent (aprotinin, aminocaproic acid) was allowed during CPB but not after weaning from CPB. Before completion of the operation, the perfusionist would tell the surgeon in which group the patient had been randomized, and the drainage system was set up accordingly. Indications for surgical re-exploration for bleeding after the cardiac operations were left to the surgeon's discretion.

Intraoperative transfusion. Intraoperative homologous blood products were administered according to the following criteria during the study period. During CPB, red blood cells were transfused for hemoglobin concentration below $60 \mathrm{~g} / \mathrm{L}$, whereas in the postoperative period the threshold for homologous red blood cell transfusion was $80 \mathrm{~g} / \mathrm{L}$. Clotting factors 
Table III. Intraoperative characteristics

\begin{tabular}{|c|c|c|c|}
\hline Characteristics & $\begin{array}{l}\text { Reinfusion group } \\
\quad(n=98)\end{array}$ & $\begin{array}{l}\text { Control group } \\
\quad(n=100)\end{array}$ & $\mathrm{P}$ value \\
\hline Duration of CPB (min) & $79 \pm 6$ & $76 \pm 5$ & .4 \\
\hline Aortic crossclamp time (min) & $51 \pm 5$ & $46 \pm 4$ & .2 \\
\hline Antifibrinolytic administration (\%) & $67(68)$ & $72(72)$ & 6 \\
\hline Intraoperative blood loss (mL) & $494 \pm 82$ & $476 \pm 51$ & .7 \\
\hline
\end{tabular}

Table IV. Exposure to homologous blood products

\begin{tabular}{lccc}
\hline \multicolumn{1}{c}{ Blood products } & Reinfusion group $(n=98)$ & Control group $(n=100)$ & P value \\
\hline Packed red blood cells & $1.8 \pm 0.7$ & $2.2 \pm 0.5$ & .5 \\
Platelets & $3.2 \pm 1.2$ & $2.7 \pm 0.9$ & .6 \\
Fresh frozen plasma & $1.3 \pm 0.7$ & $0.9 \pm 0.5$ & .4 \\
Cryoprecipitate & $0.4 \pm 0.3$ & $0.4 \pm 0.3$ & .9 \\
Total & $6.7 \pm 2.7$ & $6.4 \pm 1.8$ & .9 \\
Patients transfused (\%) & $54(55)$ & $73(73)$ & .01 \\
\hline
\end{tabular}

Data are expressed as mean number of units transfused per patient $\pm 1.96 \mathrm{SD}$ where indicated.

Table V. Coagulation profile

\begin{tabular}{|c|c|c|c|c|c|c|}
\hline & \multicolumn{3}{|c|}{ Immediately postoperative } & \multicolumn{3}{|c|}{ Postoperative day 1} \\
\hline & Reinfusion group & Control group & $\mathrm{P}$ value & Reinfusion group & Control group & $\mathrm{P}$ value \\
\hline Platelets $\left(\times 10^{9} / \mathrm{L}\right)$ & $107.3 \pm 6.7$ & $102.9 \pm 6.8$ & .4 & $121.3 \pm 6.6$ & $123.2 \pm 7.1$ & .7 \\
\hline Prothrombin time (s) & $11.7 \pm 0.5$ & $12.0 \pm 0.4$ & .4 & $9.5 \pm 0.2$ & $9.7 \pm 0.2$ & .3 \\
\hline Partial thromboplastin time (s) & $36.1 \pm 2.7$ & $40.9 \pm 3.6$ & .04 & $32.0 \pm 1.9$ & $37.0 \pm 2.7$ & .003 \\
\hline
\end{tabular}

were administered for persistent bleeding after correction of the activated clotting time. Four units of fresh frozen plasma were given for persistent moderate $(100-300 \mathrm{~mL} / \mathrm{h})$ or severe (300 $\mathrm{mL} / \mathrm{h}$ for 2 hours) bleeding with an international normalized ratio higher than 1.8 . For bleeding patients with platelet counts lower than $80 \times 10^{9} / \mathrm{L}, 8$ units of platelets were transfused, and 8 units of cryoprecipitate were administered for fibrinogen levels lower than $1.0 \mathrm{~g} / \mathrm{L}$.

Statistical analysis. The study was designed to demonstrate a decrease from $80 \%$ to $50 \%$ in the number of patients exposed to homologous blood products on the basis of the experience of de Varennes and colleagues. ${ }^{3}$ It was estimated that 200 patients had to be randomized into 2 groups. Patients were randomized in the control group or the reinfusion group by use of a table of random digits by blocks of 4 .

Blood tests and different measurements of standardized clinical data were done after a strict protocol identical in both groups. All data were prospectively collected from the chart of every enrolled patient by 3 research assistants. For the purpose of the study, the term transfusion refers to any administration of homologous blood products, including homologous packed red blood cell units, platelets, fresh frozen plasma, and cryoprecipitate units.

Data are expressed as means \pm 1.96 SEM unless otherwise specified. Statistical comparisons were done with the unpaired Student $t$ test for continuous variables and the Mantel-Haenszel test for rates of exposure. Univariate and multiple logistic regression analysis was performed to identify the relationship between the need of homologous blood transfusion after the operation and several clinical variables among autotransfused and control patients. Data analyses were performed by means of Number Cruncher Statistical System 6.0.21 software (NCSS Statistical Software, Kaysville, Utah), released March 1996, and SAS 6.12 statistical software (SAS Institute, Inc, Cary, NC).

\section{Results}

Of the 198 participants, 196 completed the study in accordance with the protocol. Two patients randomized to the reinfusion system were not subjected to the proper study protocol: in 1 case the surgeon requested to use the usual drainage system, and in the other case the postoperative protocol was not observed. The data from those 2 patients are included in the reinfusion group to perform an intent-to-treat analysis.

Reinfusion and control groups were similar for most of the clinical and demographic parameters but differed in their age, weight, and preoperative hemoglobin lev- 


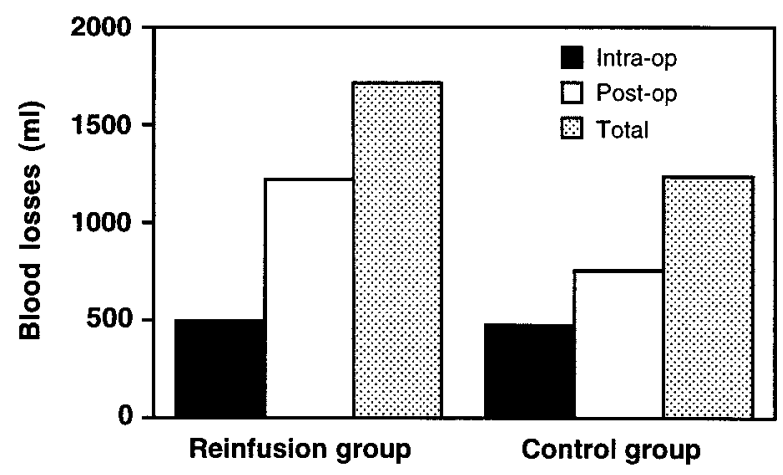

Fig 1. Blood loss during and after the operation was higher in the reinfusion group than in the control group $(P=.002)$. Intra-op, Intraoperative; post-op, postoperative; total, total blood losses.

els. Patients in the reinfusion group were younger, heavier, and had a higher baseline average hemoglobin level than control patients (Table I). There was no difference in terms of preoperative platelet counts and coagulation parameters, although one third of patients in both groups were administered intravenous heparin up until the time of the operation for unstable angina present before the operation. The number of patients who underwent coronary artery bypass grafting (CABG), valve procedures, combined operations, and redo operations was similar in the 2 groups (Table II). First-time procedures accounted for $94 \%$ and $91 \%$ of all operations in the reinfusion and control groups, respectively. Sixty-seven (69\%) patients in the reinfusion group and 72 (72\%) in the control group received intraoperative antifibrinolytic agents (aprotinin, aminocaproic acid; $P=.6$ ). The mean crossclamp time and CPB time were similar in the 2 groups (Table III).

Although intraoperative blood losses were similar in the 2 groups, the postoperative amount of blood drained in the reinfusion group was significantly higher, averaging $1200 \pm 201 \mathrm{~mL}$ compared with $758 \pm 152 \mathrm{~mL}$ in the control group ( $P=.0007$, Fig 1$)$. Thus, the total blood loss (intraoperative and postoperative) was higher in the reinfusion group, averaging $1684 \pm 228 \mathrm{~mL}$ compared with $1233 \pm 171 \mathrm{~mL}$ in the control group $(P=.002)$. The mean volume of autotransfused shed blood was $722 \pm$ $105 \mathrm{~mL}$ (range, $0-2660 \mathrm{~mL}$ ) in the reinfusion group. The mean number of homologous blood products transfused per patient was similar in the 2 groups, but only $55 \%$ of patients reinfused received homologous blood products compared with $73 \%$ in the control group, a significant difference between the 2 groups $(P=.01$, Table IV). The average hemoglobin level was significantly lower in the control group throughout the entire study, as was the red cell mass (hemoglobin $\times$ body surface area). There was no effect of reinfusion of autologous blood on measured coagulation parameters, as shown in Table $\mathrm{V}$.

Univariate analyses performed to define a target group of patients who would most benefit from reinfusion showed that older age, male sex, and an increased amount of drainage through chest tubes were associated with an increased need of transfusions. On the other hand, higher preoperative red cell mass, use of an antifibrinolytic agent, and use of the reinfusion system were associated with a lower number of transfusions (Table VI). On multivariate analysis, male sex and the amount of drainage through chest tubes are still related to an increased risk of transfusion. Higher preoperative red cell mass and reinfusion of mediastinal blood collected with a closed system at $-20 \mathrm{~cm} \mathrm{H}_{2} \mathrm{O}$ are related to a decreased risk of any type of homologous blood transfusion (Table VII).

The overall reoperation rate for bleeding was $7 \%$ in the reinfusion group and $8 \%$ in the control group (not significant). Cerebrovascular accident or transient ischemic attack occurred in 1 reinfused patient and 2 control subjects. Atrial arrhythmia occurred in 29 patients (16 reinfused patients and 13 control subjects, $P=$ not significant), and myocardial infarction occurred in 7 patients (5 reinfused patients and 2 control subjects, $P=$ not significant). There were 2 in-hospital deaths (mortality rate of $1 \%$ ) from perioperative myocardial infarction, both in the control group.

\section{Discussion}

The present prospective randomized trial demonstrates an 18\% decrease (from 73\%-55\%) in the number of patients exposed to homologous blood products after $\mathrm{CABG}$, valvular procedures, or both, with the use of a reinfusion system allowing autotransfusion of the shed mediastinal blood. However, there was no difference in the average number of homologous blood products per patient in the 2 groups. The amount of postoperative blood loss after the operation was greater in the reinfused group than in the control group, a difference that remains unexplained.

The present study concurs with those reported by de Varennes and colleagues, ${ }^{3}$ who showed a decrease in transfusion rates from $82 \%$ to $48 \%$ in their nonrandomized study. The unusually high transfusion rate for the control group of de Varennes and colleagues and in our control group remains within the range reported by Goodnough and colleagues ${ }^{14}$ of $68 \%$ for homologous red blood cell transfusion from 18 US institutions. However, other studies have shown that it is possible to perform cardiac operations without homologous red blood cell transfusion ${ }^{15}$ or at least with lower rates of 
Table VI. Univariate analysis of the determinants of transfusion requirement for all patients

\begin{tabular}{llrc}
\hline \multicolumn{1}{c}{ Characteristics } & \multicolumn{2}{c}{ Odds ratio $(95 \%$ CI) } & P value \\
\hline Age $(\mathrm{y})$ & 1.06 & $(1.02-1.10)$ & .0002 \\
Sex (male) & 6.36 & $(2.56-15.82)$ & .00007 \\
Preoperative red cell mass $\left(\mathrm{g} \cdot \mathrm{L}^{-1} \cdot \mathrm{m}^{-2}\right)$ & 0.97 & $(0.96-0.98)$ & $<.00001$ \\
Antifibrinolytic agent & 0.302 & $(0.15-0.63)$ & .001 \\
Mediastinal drainage $(\mathrm{mL})$ & 1.001 & $(1.0005-1.002)$ & .0002 \\
Reinfusion of mediastinal blood & 0.45 & $(0.25-0.82)$ & .009 \\
\hline
\end{tabular}

CI, Confidence interval.

Table VII. Multivariate analysis of the determinants of transfusion requirement for all patients

\begin{tabular}{llcc}
\hline \multicolumn{1}{c}{ Characteristics } & \multicolumn{2}{c}{ Odds ratio $(95 \%$ CI $)$} & P value \\
\hline Age $(\mathrm{y})$ & 1.03 & $(1.007-1.06)$ & .2 \\
Sex (male) & 3.73 & $(2.02-6.90)$ & .03 \\
Preoperative red cell mass $\left(\mathrm{g} \cdot \mathrm{L}^{-1} \cdot \mathrm{m}^{-2}\right)$ & 0.97 & $(0.965-0.98)$ & .00006 \\
Antifibrinolytic agent & 0.78 & $(0.47-1.29)$ & .6 \\
Mediastinal drainage $(\mathrm{mL})$ & 1.002 & $(1.0018-1.003)$ & .00002 \\
Reinfusion of mediastinal blood & 0.24 & $(0.15-0.38)$ & .002 \\
\hline
\end{tabular}

CI, Confidence interval.

homologous red blood cell transfusion, ranging from $10 \%$ to $25 \%$ of patients in the perioperative period. ${ }^{16}$

The mean number of homologous blood products required per patient was similar in the 2 groups. Goodnough and colleagues ${ }^{14}$ reported that their patients undergoing CABG were administered an average of $2.9 \pm 0.1$ red blood cell units, $33 \%$ of patients were administered plasma, and $22 \%$ of patients received platelet transfusion at a higher volume and higher rates than those of the present study. Body and colleagues ${ }^{17}$ showed that $41 \%$ of patients undergoing elective primary CABG in 12 US academic medical centers were administered red blood cell transfusion, with a mean transfusion volume of $2.4 \pm 1.7$ units. Moreover, platelets, fresh frozen plasma, and cryoprecipitate units were also administered.

Contrary to Body and colleagues, ${ }^{17}$ who not only concluded that there was no benefit to transfusion of shed mediastinal blood after elective CABG but who also reported a higher rate of surgical wound infection among reinfused patients, no wound infection was observed in the present study nor were any other significant side effects observed. Only one early postoperative sternal wound dehiscence occurred in each group.

Although the amount of mediastinal blood loss was higher in the reinfused group of patients, all coagulation parameters measured in the present study remained in the normal ranges. Several authors have suggested that transfusion of mediastinal shed blood may cause a significant coagulopathy. ${ }^{18}$ We can hypothesize that some proinflammatory products present in mediastinal shed blood, such as interleukin 6 , may contribute to more important wound oozing and surgical bleeding in autotransfused patients. ${ }^{19}$

Studies have also demonstrated that creatine kinaseMB (CK-MB) blood levels increase when mediastinal shed blood is reinfused and that measurement of cardiac troponin is more specific and reliable in these patients. ${ }^{20,21}$ Our data confirm that the concentrations of CK and CK-MB increase significantly and transiently on day 1 but stay within normal limits $(95 \%$ confidence interval of 20.7-30.6 for CK-MB in the control group vs 31.7-44.4 for the reinfusion group, $P$ $=.002$ ). The troponin levels remained similar in the 2 groups throughout the postoperative course.

The present study recruited a heterogenous group of patients undergoing CABG and valvular and redo operations because we expected to include higher risk patients. Although this led to some difference in baseline characteristics of patients between the 2 groups, multivariate analyses suggested that patients who would probably benefit the most from reinfusion of mediastinal shed blood are men with low body surface areas, low preoperative hemoglobin levels, and increased blood loss after their operations. Page and colleagues $^{22}$ have found that the homologous blood requirement was significantly reduced with autotransfusion of mediastinal shed blood in patients whose blood loss exceeded $500 \mathrm{~mL}$ after their operations. Unfortunately, this subgroup of patients cannot be easily identified preoperatively. In our control group, 47 (47\%) patients had postoperative blood loss greater than $500 \mathrm{~mL}$. Thus 1 in 2 patients could probably benefit from reinfusion of mediastinal shed blood. 
We understand that the use of homologous blood products in $73 \%$ and $55 \%$ of control and reinfused patients after various cardiac surgical operations remains a high rate of use of blood transfusion. In a recent multicenter controlled clinical trial that enrolled 838 critically ill patients and compared a restrictive with a liberal strategy of red cell transfusion in intensive care units, Hébert and colleagues ${ }^{23}$ have shown that the restrictive strategy, with a threshold for hemoglobin concentration of $7 \mathrm{~g} / \mathrm{dL}$, was at least as effective and possibly superior in terms of the 30-day mortality compared with a liberal strategy of transfusion. Thus, the recommendation of Hébert and colleagues, stating that critically ill patients receive red cell transfusions only when their hemoglobin concentrations fall below $7 \mathrm{~g} / \mathrm{dL}$ and that hemoglobin concentration should be maintained between 7 and $9 \mathrm{~g} / \mathrm{dL}$, could further reduce the need for homologous blood transfusion in patients after cardiac operations.

In summary, we confirm that the autotransfusion of mediastinal shed blood after cardiac operations is safe and reduces the number of patients exposed to homologous blood products. Preoperative determinants of patients who would most benefit from autotransfusion of mediastinal shed blood includes male sex, anemic status, and lower body surface area. The exact cause of increased shed blood in reinfused patients despite normal coagulation parameters remains unclear but could be simply related to a greater mechanical efficacy of the autotransfusion closed drainage system compared with the effect of soft sump drains used in the control group of patients.

\section{REFERENCES}

1. Schaff HV, Hauer JM, Bell WR, Gardner TJ, Donahoo JS, Gott VL, et al. Autotransfusion of shed mediastinal blood after cardiac surgery: a prospective study. J Thorac Cardiovasc Surg 1978;75:632-41.

2. Schmidt H, Mortensen PE, Folsgaard SL, Jensen EA. Autotransfusion after coronary artery bypass grafting halves the number of patients needing blood transfusion. Ann Thorac Surg 1996;61:1177-81.

3. de Varennes B, Nguyen D, Denis F, Ergina P, Latter D, Morin JE. Reinfusion of mediastinal blood in CABG patients: impact on homologous transfusions and rate of re-exploration. J Card Surg 1996;11:387-95.

4. Morris JJ, Tan YS. Autotransfusion: Is there a benefit in a current practice of aggressive blood conservation? Ann Thorac Surg 1994;58:502-8

5. Schaff HV, Hauer J, Gardner TJ, Donahoo JS, Watkins L Jr, Gott $\mathrm{VL}$, et al. Routine use of autotransfusion following cardiac surgery: experience in 700 patients. Ann Thorac Surg 1979;27:493-9.

6. Thurer RL, Lytle BW, Cosgrove DM, Loop FD. Autotransfusion following cardiac operations: a randomized, prospective study. Ann Thorac Surg 1979;27:500-7.

7. Roberts SR, Early GL, Brown B, Hannah H 3rd, McDonald HL. Autotransfusion of unwashed mediastinal shed blood fails to decrease banked blood requirements in patients undergoing aortocoronary bypass surgery. Am J Surg 1991;162:477-80.

8. Bouboulis N, Kardara M, Kesteven PJ, Jayakrishnan AG. Autotransfusion after coronary artery bypass surgery: Is there any benefit? J Card Surg 1994;9:314-21.

9. Schirmer U, Hemmer W, Lindner KH, Goertz A, Schutz W, Georgieff M. Shed mediastinal blood in 500 elective cardiac surgery patients: Is there enough for retransfusion routinely? JCardiovasc Surg 1997;38:45-50.

10. Vertrees RA, Conti VR, Lick SD, Zwischenberger JB, McDaniel LB, Shulman G. Adverse effects of postoperative infusion of shed mediastinal blood. Ann Thorac Surg 1996;62:717-23.

11. Hartz RS, Smith JA, Green D. Autotransfusion after cardiac operation: assessment of hemostatic factors. J Thorac Cardiovasc Surg 1988;96:178-82.

12. Axford TC, Dearani JA, Ragno G, MacGregor H, Patel MA, Valeri CR, et al. Safety and therapeutic effectiveness of reinfused shed blood after open heart surgery. Ann Thorac Surg 1994;57:615-22.

13. Kongsgaard UE, Tollofsrud S, Brosstad F, Ovrum E, Bjornskau L. Autotransfusion after open heart surgery: characteristics of shed mediastinal blood and its influence on the plasma proteases in circulating blood. Acta Anaesthesiol Scand 1991;35:71-6.

14. Goodnough LT, Johnston MF, Toy PT. The variability of transfusion practice in coronary artery bypass surgery. Transfusion Medicine Academic Award Group. JAMA 1991;265:86-90.

15. Helm RE, Rosengart TK, Gomez M, Klemperer JD, DeBois WJ, Velasco F, et al. Comprehensive multimodality blood conservation: 100 consecutive CABG operations without transfusion. Ann Thorac Surg 1998;65:125-36.

16. Goodnough LT, Despotis GJ. Establishing practice guidelines for surgical blood management. Am J Surg 1995;170(Suppl 6A): $16 \mathrm{~S}-20 \mathrm{~S}$.

17. Body SC, Birmingham J, Parks R, Ley C, Maddi R, Shernan SK, et al. Safety and efficacy of shed mediastinal blood transfusion after cardiac surgery: a multicenter observational study. Multicenter Study of Perioperative Ischemia Research Group. JCardiothorac Vasc Anesth 1999;13:410-6.

18. de Haan J, Boonstra PW, Monnink SH, Ebels T, van Oeveren W. Retransfusion of suctioned blood during cardiopulmonary bypass impairs hemostasis. Ann Thorac Surg 1995;59:901-7.

19. Bengtsson A, Avall A, Hyllner M, Bengtson JP. Formation of complement split products and proinflammatory cytokines by reinfusion of shed autologous blood. Toxicol Lett 1998;23:129-33.

20. Nguyen DM, Gilfix BM, Dennis F, Blank D, Latter DA, Ergina PL, et al. Impact of transfusion of mediastinal shed blood on serum levels of cardiac enzymes. Ann Thorac Surg 1996;62:109-14.

21. De Paulis R, Colagrande L, Seddio F, Piciche M, Penta de Peppo A, Bassano C, et al. Levels of troponin I and cardiac enzymes after reinfusion of shed blood in coronary operations. Ann Thorac Surg 1998;65:1617-20.

22. Page R, Russell GN, Fox MA, Fabri BM, Lewis I, Williets T. Hard-shell cardiotomy reservoir for reinfusion of shed mediastinal blood. Ann Thorac Surg 1989;48:514-7.

23. Hebert PC, Wells G, Blajchman MA, Marshall J, Martin C, Pagliarello G, et al. A multicenter, randomized, controlled clinical trial of transfusion requirements in critical care. Transfusion Requirements in Critical Care Investigators, Canadian Critical Care Trials Group. N Engl J Med 1999;340:409-17. 